Supplementary Materials

\title{
Selective activation of S or N-containing carbon segments by alkalic or acidic activators
}

Yanming $\mathrm{Cao}^{\mathrm{a}, \dagger}$, Guoqing Ninga, ${ }^{\mathrm{a},{ }^{*},}$, Chenggen $\mathrm{Xu}^{\mathrm{a}}$, Xiaoqiao Huang ${ }^{\mathrm{b}, \mathrm{c}}$, Yintao $\mathrm{Yu}^{\mathrm{a}}$, Wei Lia ${ }^{a}$ Chunming $\mathrm{Xu}^{\mathrm{a}}$

aState Key Laboratory of Heavy Oil Processing, China University of Petroleum, Beijing, 102249, China

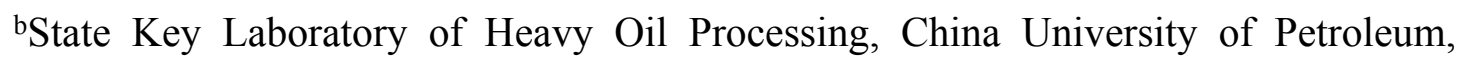
Qingdao, 266580, China

'Petrochina Fuel Oil Company Limited Research Institute, Beijing, 100195, China

$\dagger$ These author contributed equally.

*Corresponding author. E-mail: ngq@cup.edu.cn (G. Ning) 


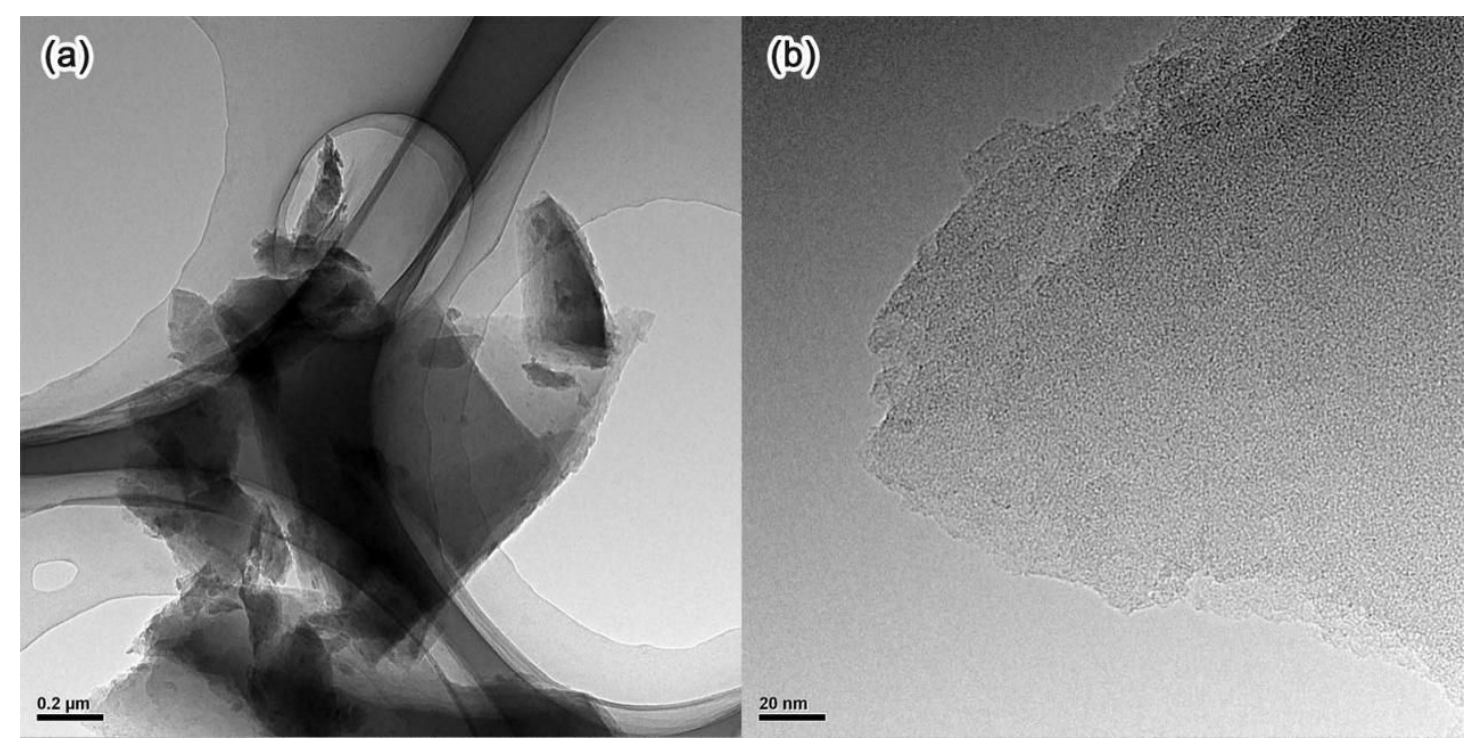

Figure S1 Low (a) and high magnification (b) TEM images of the undoped petroleum coke.
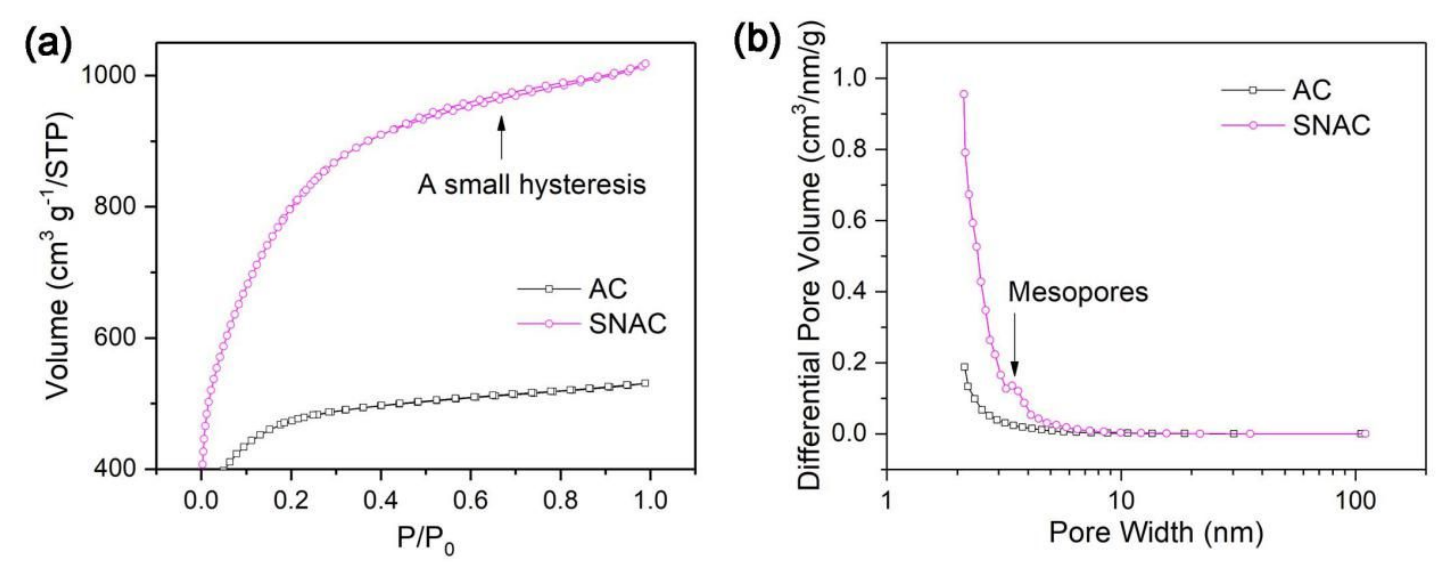

Figure S2 Magnified $\mathrm{N}_{2}$ adsorption-desorption curves (a) and pore size distributions (b) for SNAC and AC. 


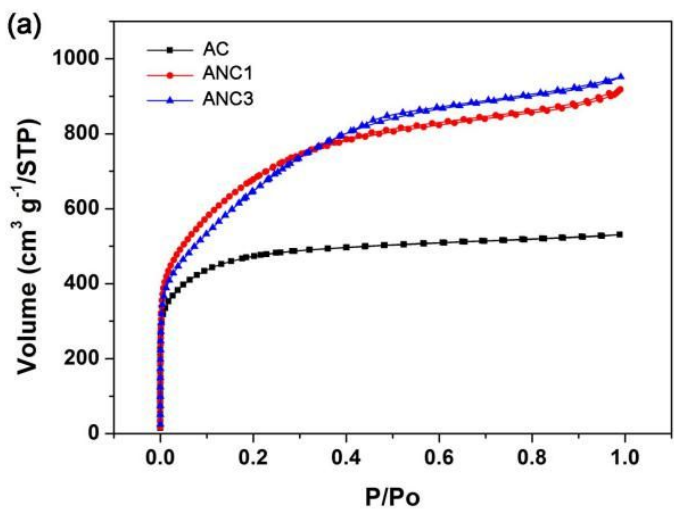

(b)
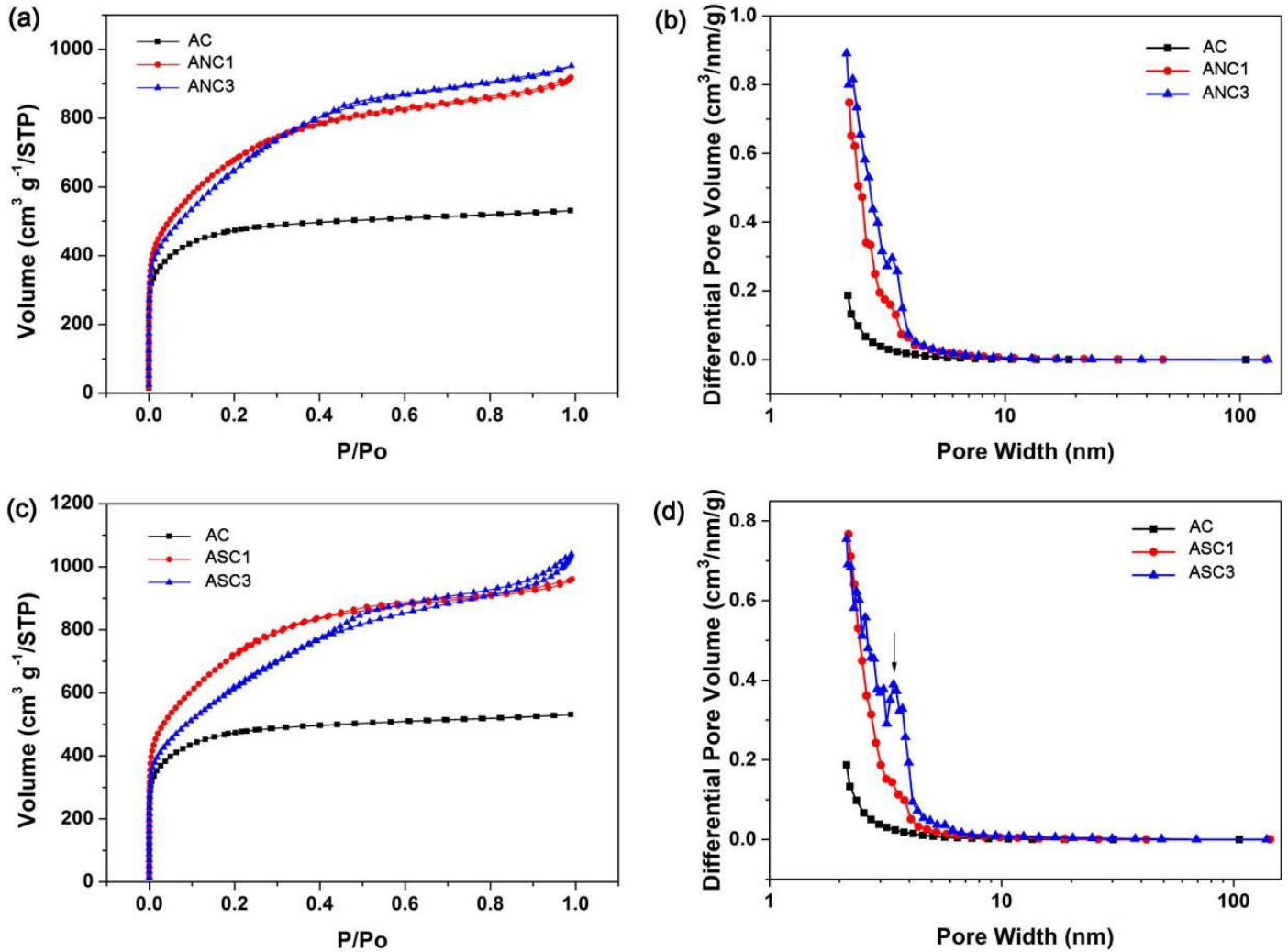

Figure $\mathrm{S} 3 \mathrm{~N}_{2}$ adsorption-desorption curves (a, c) and pore size distributions (b, d) for ANC and ASC samples, in comparison with AC. The ANC prepared with a melamine to vacuum residue ratio of 1:1 is labeled as $\mathrm{ANC1}$, and that prepared with a melamine to vacuum residue ratio of 3:1 is labeled as ANC3; the ASC prepared with a $\mathrm{MgSO}_{4}$ to vacuum residue ratio of 1:1 is labeled as $\mathrm{ASCl}$, and that prepared with a $\mathrm{MgSO}_{4}$ to vacuum residue ratio of 3:1 is labeled as ASC3. More mesopores are formed after adding melamine or $\mathrm{MgSO}_{4}$, indicating that the $\mathrm{N}$ source or $\mathrm{S}$ source is also capable of introducing mesopores to the final products. The hysteresis loop for ASC3 is obviously larger than $\mathrm{ANC} 3$, because $\mathrm{MgSO}_{4}$ or $\mathrm{MgO}$ is much stabler than melamine at high temperature and can maintain the pore structure more efficiently. 


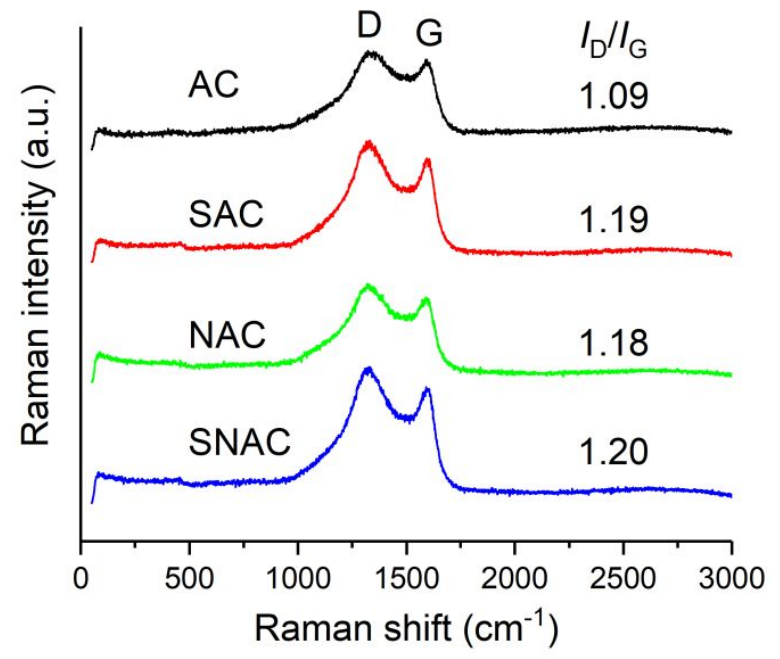

Figure S4 Raman spectra of the as-prepared samples. 
(a) SNC

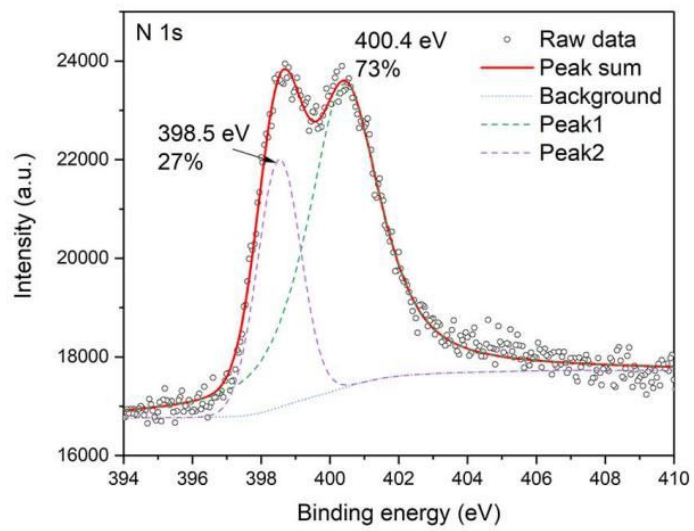

(c) ASNC- $\mathrm{H}_{2} \mathrm{O}$

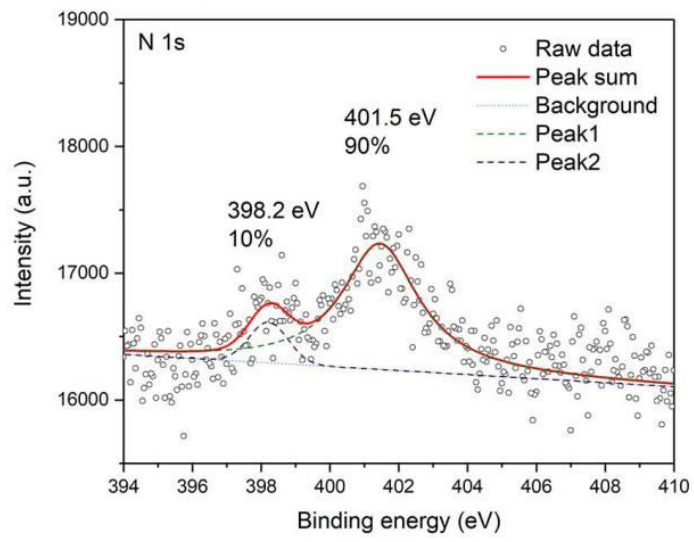

(b) $\mathrm{ASNC}-\mathrm{CO}_{2}$

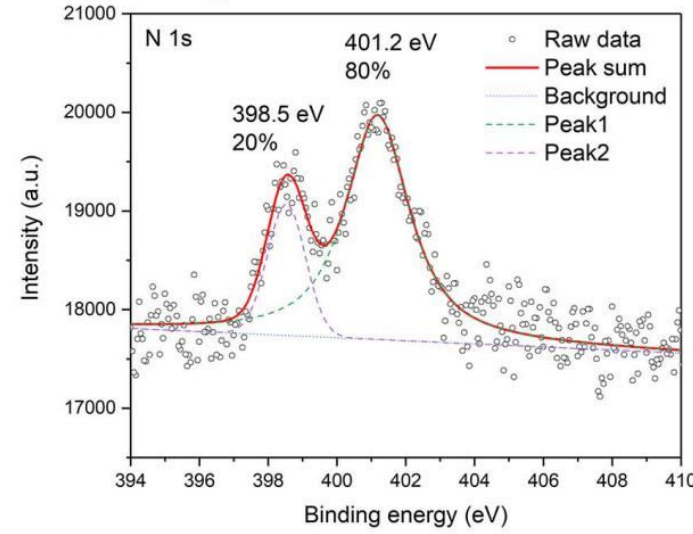

(d) ASNC-NH

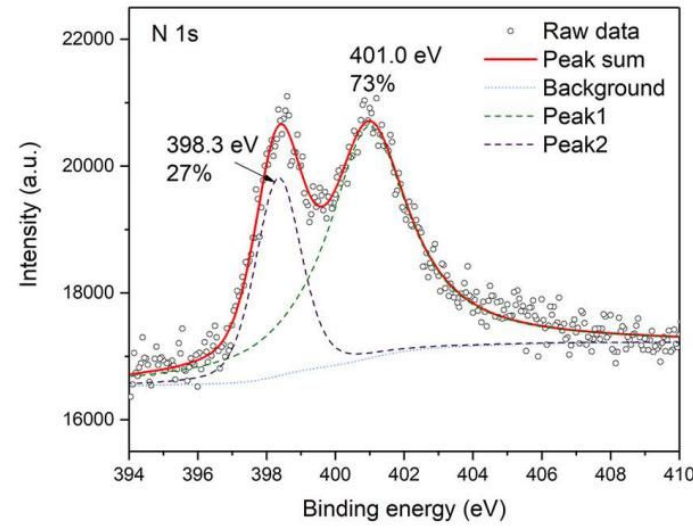

Figure S5 Peak fitting of N 1s peaks for SNC (a), ASNC-CO $\mathrm{CO}_{2}(\mathrm{~b}), \mathrm{ASNC}-\mathrm{H}_{2} \mathrm{O}$ (c) and $\mathrm{ASNC}-\mathrm{NH}_{3}(\mathrm{~d})$. 

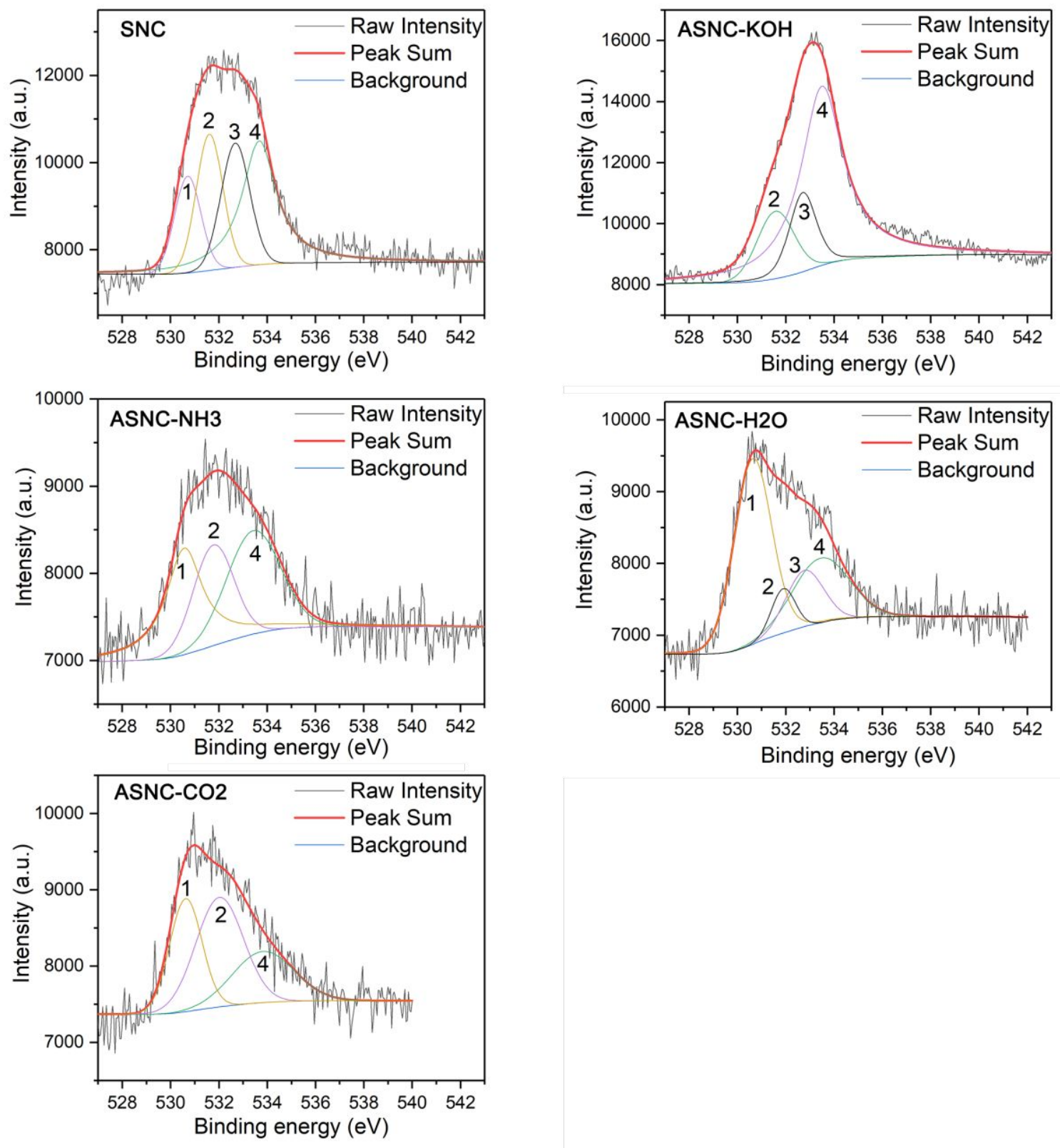

Figure S6 Peak fitting of the O 1s peaks of the as-prepared ACs. Assignment: 1, quinone; 2, $\mathrm{C}=\mathrm{O} ; 3, \mathrm{C}-\mathrm{O} ; 4, \mathrm{O}-\mathrm{H}$. 